\title{
Cyclooxygenase-1 gene polymorphisms in patients with different asthma phenotypes and atopy
}

\author{
J. Shi**\#, , N.L.A. Misso**\#, D.L. Duffy ${ }^{+}$, B. Bradley**\#, , R. Beard**\#, \\ P.J. Thompson**\# and M-A. Kedda*,\#,"
}

ABSTRACT: Cyclooxygenase-1 (COX-1) regulates the biosynthesis of prostaglandins, which are important mediators in asthma. The possible association of COX-1 gene polymorphisms with asthma has not been investigated.

The allele frequencies of $20 \mathrm{COX}-1$ polymorphisms were determined in a random Australian Caucasian population using MassARRAY technology. Informative and potentially functional promoter (c.8592C $>$ T, c.1676C $>T$ ) and coding region (c.22C $>T$, c.50C $>T$ ) polymorphisms were investigated in carefully phenotyped patients with mild $(n=316)$, moderate $(n=241)$, severe $(n=86)$ or aspirin-intolerant asthma (AIA) $(n=58)$, and in nonasthmatic subjects $(n=477)$.

There were no allelic, genotypic or haplotypic associations between these four polymorphisms and asthma or asthma severity. Over-representation of the c.50TT genotype among AIA patients (3.4\%) compared with aspirin-tolerant patients $(0.8 \%)$, and a global haplotype association with AIA did not reach statistical significance. The c.22TT genotype was less frequent among atopic $(0.1 \%)$ rather than nonatopic individuals $(1.2 \%$; odds ratio $=9.05,95 \%$ confidence interval $1.01-$ 81.29).

In conclusion, the present investigation of cyclooxygenase-1 polymorphisms in asthma indicates that they do not appear to play a substantial role in genetic pre-disposition for asthma or asthma severity. However, the c.22TT genotype confers a small protective effect against atopy. Potential associations with aspirin-intolerant asthma were identified and warrant further investigation in a larger population of aspirin-intolerant asthma patients.

KEYWORDS: Aspirin-induced asthma, asthma, atopy, cyclooxygenase-1, haplotypes, polymorphism

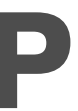

rostaglandins (PGs) are important lipid mediators that have pro-inflammatory as well as anti-inflammatory and bronchoprotective roles in human airways [1-3]. Cyclooxygenase (COX) is the key enzyme, which together with tissue-specific synthases, regulates the synthesis of PGs from arachidonic acid $[4,5]$. Three isoforms of COX have been described, with COX-1 and COX-3 being splice variants of the same gene [6], while COX-2 is encoded by a different gene. COX-2 is an inducible enzyme responsible for the synthesis of PGs in a variety of inflammatory states [7]. COX-1 has traditionally been regarded as a constitutively expressed enzyme that generates PGs for cell-cell signalling, blood clotting, and maintenance of renal function, tissue homeostasis and gastrointestinal integrity [4, 7]. However, COX-1 is also thought to play a role in pathophysiological processes, including inflammation, arthritic disease and cancer, and while there is evidence that COX-1 expression may be regulated, little is known about the mechanisms involved [8,9]. COX-1 and COX-2 are both constitutively expressed in epithelial cells of the airways [10, 11], and $\mathrm{PGE}_{2}$, produced by these enzymes, may have a protective function in the airways of asthmatic patients, similar to that of COX-1-derived prostanoids in the gastrointestinal tract and vasculature [12].

Aspirin-intolerant asthma (AIA) is a specific subtype of asthma characterised by chronic rhinosinusitis and nasal polyposis, with symptoms developing after the third decade of life, following the ingestion of aspirin and other nonsteroidal anti-inflammatory drugs (NSAIDs) [13]. Aspirin and NSAIDs, which trigger asthma in $3-20 \%$ of adult patients [14-16], are potent

\section{AFFILIATIONS}

${ }^{*}$ Cooperative Research Centre for Asthma,

\#Asthma and Allergy Research Institute (Inc.) and Centre for Asthma Allergy and Respiratory Research, "Western Australian Institute for Medical Research and Centre for Medical Research, The University of Western Australia, Perth, and +Genetic Epidemiology Laboratory, Queensland Institute of Medical Research, Brisbane, Australia.

CORRESPONDENCE

P.J. Thompson

Asthma and Allergy Research

Institute

Ground Floor

E Block

Sir Charles Gairdner Hospital

Nedlands

WA 6009

Australia

Fax: 61893464159

E-mail: aari@aari.uwa.edu.au

Received

December 092004

Accepted after revision:

April 232005

SUPPORT STATEMENT

This study was funded by the Cooperative Research Centre for Asthma, the Asthma and Allergy Research Institute (Inc.), and the National Health and Medical Research Council of Australia (NHMRC), Canberra, Australia. D.L. Duffy is a NHMRC Research Fellow. 
irreversible inhibitors of COX-1, whereas specific COX-2 inhibitors do not appear to precipitate episodes of asthma [17]. Therefore, inhibition of COX-1 may be a major contributing factor in the pathogenesis of AIA [13].

The COX-1 (PG-endoperoxide synthase 1 (PTGS1)) gene is located on chromosome 9q32, and comprises 11 exons spanning a length of $22 \mathrm{~kb}$. The major transcription start site is located 136 bases upstream from the ATG initiation codon [18]. Multiple transcription factor binding sites have been identified in the promoter, including two Sp1 binding sites that appear to be important in basal gene transcription [19]. Limited investigations of the COX-1 gene have identified 13 coding regions and five intronic polymorphisms in 48 AfricanAmerican and 47 Caucasian healthy individuals [20], as well as one additional coding region and three promoter polymorphisms in 38 healthy individuals of Caucasian descent [21].

Although the present authors recently reported that a functional polymorphism in the COX-2 gene promoter was not associated with asthma [22], another study reported a sex association and functional effects of this polymorphism in asthma [23]. Single nucleotide polymorphisms (SNPs) in the COX-1 gene may also have profound effects on COX-1 expression and PG biosynthesis, and, directly or indirectly, influence the pathogenesis, development and severity of asthma and atopy as well as response to therapies. Therefore, in this study, a large, well-phenotyped Australian Caucasian population was investigated to determine whether there are allelic, genotype or haplotypic associations between COX-1 gene polymorphisms and asthma, asthma severity, aspirin intolerance or atopy. To the best of the present authors' knowledge, this is the first detailed investigation of potential associations between variants of the COX-1 gene and asthma.

\section{METHODS \\ Subjects}

The frequencies of COX-1 polymorphisms in the general population were determined using random blood samples collected from 176 Australian Caucasian donors at the Red Cross Blood Bank in Perth, Western Australia. The association studies included 477 healthy control individuals and 643 patients with asthma, including 316 subjects with mild, 241 with moderate and 86 with severe asthma, as well as 58 individuals with AIA. Asthma was defined as physiciandiagnosed asthma. Although no reversibility or hyperresponsiveness testing was performed at the time of recruitment, many patients have had such tests performed in the past. All subjects were unrelated and aged $20-89$ yrs. The participants were recruited by random mail-out, except for patients with more severe asthma and AIA, who were also recruited via physician referrals. All subjects gave written informed consent and were personally interviewed by respiratory staff with experience of asthma and chronic obstructive pulmonary disease patients on a daily basis. Subjects completed a detailed questionnaire about asthma, respiratory health and other health-related matters, had their lung function assessed by spirometry and provided blood samples $(10 \mathrm{~mL})$ for genotyping analysis. Nonasthmatic subjects had no history of asthma, chronic respiratory disease or other serious disease, but it is possible that some of these subjects may have had nasal (allergic rhinitis) or skin (atopic eczema) manifestations of atopy that were not declared. The study protocol was approved by the Human Research Ethics Committees of the Sir Charles Gairdner Hospital (Perth), The Prince Charles Hospital (Brisbane), and The Alfred Hospital (Melbourne, Australia).

\section{Classification of clinical phenotypes}

The patients were classified as having mild, moderate or severe asthma, according to the criteria specified by the Australian National Asthma Council and the National Institutes of Health [24, 25]. These criteria, which have been described in detail previously [26], included lung function, use of oral corticosteroids in the last 12 months, daily inhaled corticosteroid dose, frequency of rescue medication use, frequency of daytime symptoms, frequency of night-time awakening due to asthma, unplanned visits to a general practitioner in the last 12 months and hospital admissions for asthma in the last 12 months. The asthma patients were also classified as having AIA or aspirin-tolerant asthma (ATA) using a separate questionnaire that has previously been used to assess the prevalence of aspirin intolerance in asthmatic patients [16]. For 27 out of 58 patients, the diagnosis of AIA had been confirmed by aspirin challenge, and the remaining 31 patients had strong histories of aspirin/NSAID-induced asthma, with classical clinical features occurring on multiple occasions shortly after ingestion of the drug.

\section{Atopy testing}

Assessment of atopic status was based on a skin-prick reaction (with a wheal diameter $\geqslant 3 \mathrm{~mm}$ ) to at least one of five common aeroallergens, including cat, dog, house dust mite, mould mix (Alternaria tenuis, Aspergillus spp. mix, Cladosporium spp., Penicillium spp. mix) and grass pollen mix (Kentucky Blue, Orchard, Red Top, Timothy, Sweet Vernal, Meadow Fescue, Perennial Rye; Hollister-Stier, Spokane, WA, USA).

\section{Selection of polymorphisms}

A total of 20 polymorphisms located in the promoter and coding region of the COX-1 (PTGS1) gene were identified by searching the National Center for Biotechnology Information (NCBI) website (www.ncbi.nlm.nih.gov/SNP) and SNPper databases [27]. The positions of the polymorphisms in the gene were confirmed using the basic local alignment search tool program [28] to align the dbSNP cluster sequences with the COX-1 DNA sequence (GenBank accession no. AF440204). Random Australian Caucasian subjects $(n=176)$ were initially genotyped for these 20 SNPs. Selection of SNPs for further genotyping in the asthmatic and nonasthmatic subjects was based on the following criteria: 1 ) a frequency $>5 \%$ in the random Caucasian subjects, and 2) the SNPs had potential functional consequences due to their location in transcription factor binding sites, or because they resulted in amino acid changes that were likely to alter protein function. A total of four out of the 10 SNPs that were detected in the random Caucasian subjects satisfied both these criteria and were, therefore, selected for genotyping in the asthmatic and nonasthmatic subjects.

\section{Genotype analysis}

DNA was extracted from peripheral blood leukocytes using a DNA extraction kit (Qiagen, Hilden, Germany), according to the manufacturer's instructions. Genotyping of the 
c. $-1676 \mathrm{C}>\mathrm{T}$, c. $-8592 \mathrm{C}>\mathrm{T}, \mathrm{c} .22 \mathrm{C}>\mathrm{T}$ and c.50C $>\mathrm{T}$ polymorphisms was performed using the MassARRAY system (Sequenom Inc., San Diego, CA, USA), commercially available at the Australian Genome Research Facility (Brisbane, Australia). Briefly, following PCR amplification, primer extension products were analysed by chip-based matrix-assisted laser desorption ionisation time-of-flight (MALDI-TOF) mass spectrometry. Primers were designed using Sequenom software, and the extension reaction produced allele-specific products with masses differing by $\sim 300 \mathrm{Da}$, or approximately one single nucleotide. Primer extension and PCR were performed according to the manufacturer's instructions, using Thermosequenase (Sequenom) and HotStarTaq DNA polymerase (Qiagen). After desalting of the reaction products (SpectroCLEAN; Sequenom), $\sim 10 \mathrm{~nL}$ were loaded into a SpectroCHIP (Sequenom) and analysed in the MALDI-TOF MassARRAY system in the fully automated mode. Genotypes were automatically identified by the SpectroTYPER software (Sequenom), and only conservative and moderate calls, as defined by the software, were accepted for this study. As the Sequenom analysis was unsuccessful in some samples, there was minor variation in the numbers of subjects investigated for the different polymorphisms.

\section{Statistical methods}

Genotype and allele frequencies were calculated for each group of patients. Univariate comparisons of allele and genotype distributions were performed using Chi-squared tests and logistic regression analysis with the $\mathrm{R}$ Statistics Program [29]. Hardy-Weinberg equilibrium analysis for each group was evaluated by the exact test, implemented in the $\mathrm{R}$ Statistics program. The haplotype results were obtained using the haplo.stats library of SCHAID et al. [30].

\section{RESULTS}

\section{SNPs in the promoter and exons of the COX-1 gene}

A total of 20 polymorphisms, six in the promoter and 14 (12 nonsynonymous, two synonymous mutations) in the coding region of the gene, were identified in the NCBI and SNPper databases [27]. Of the 13 exonic SNPs investigated in a recent study of African-American and Caucasian healthy individuals [20], nine were investigated in the present random Caucasian population, but four synonymous mutations were not. For 10 previously described SNPs, the frequencies were so low that the minor alleles were not detected in any of the 176 random Caucasian subjects. For the 10 polymorphisms that were detected, their positions in the gene, the putative transcription factor binding sites affected [31] or resulting amino acid substitutions, and the allele frequencies in 176 random Australian Caucasian individuals are shown in table 1. For six SNPs, the minor allele frequencies were $<5 \%$, and these relatively uncommon mutations were not studied any further. The remaining polymorphisms, c. $-1676 \mathrm{C}>\mathrm{T}$ and c. $-8592 \mathrm{C}>\mathrm{T}$ in the promoter, and c. $22 \mathrm{C}>\mathrm{T}$ and c. $50 \mathrm{C}>\mathrm{T}$ in the coding region, were investigated in the asthmatic and non-asthmatic populations.

\section{Association analysis}

The demographic and phenotypic characteristics of the asthmatic and control populations are presented in table 2. The prevalence of atopy was greater among the asthmatic than the nonasthmatic subjects $(\mathrm{p}<0.0001)$. Although eight different criteria were used, the final categorisation of disease severity appeared to be closely related to mean data for lung function and medication use. Among the AIA patients, 21 were classified as having mild, 25 moderate and 12 severe asthma.

The genotype and allele frequencies for the c. $-1676 \mathrm{C}>\mathrm{T}$, c.$8592 \mathrm{C}>\mathrm{T}, \mathrm{c} .22 \mathrm{C}>\mathrm{T}$ and c.50C $>\mathrm{T}$ polymorphisms in all asthma patients, and when categorised by asthma severity, as well as the frequencies in nonasthmatic subjects, are presented in table 3. All four SNPs were in Hardy-Weinberg equilibrium in the present population $(p \geqslant 0.17)$. The minor allele frequencies were $\sim 21 \%$ for c. $-1676 \mathrm{C}>\mathrm{T}$ and c. $-8592 \mathrm{C}>\mathrm{T}$ and between 6.4 and $7.8 \%$ for c. $22 \mathrm{C}>\mathrm{T}$ and c. $50 \mathrm{C}>\mathrm{T}$, in asthmatic and nonasthmatic subjects. There were no statistically significant differences between the asthmatic and nonasthmatic subjects

\begin{tabular}{|c|c|c|c|c|c|}
\hline $\begin{array}{ll}\text { TABLE } 1 & \text { Ch } \\
& \text { (CC }\end{array}$ & $\begin{array}{l}\text { cs of the } \\
\text { e and th }\end{array}$ & $\begin{array}{l}\text { ucleotide polymorph } \\
\text { frequencies in a ra }\end{array}$ & $\begin{array}{l}\text { NPs) in the } \\
\text { ustralian } \mathrm{Ca}\end{array}$ & $\begin{array}{l}\text { er and coding regio } \\
\text { population }\end{array}$ & yclooxygenase \\
\hline $\begin{array}{l}\text { dbSNP rs } \\
\text { number cluster ID }\end{array}$ & Region & $\begin{array}{l}\text { SNP location (cDNA) } \\
\text { GenBank accession } \\
\text { number: NM } 000962\end{array}$ & $\begin{array}{l}\text { Minor allele } \\
\text { frequency }\end{array}$ & $\begin{array}{l}\text { Putative transcription } \\
\text { factor binding sites } \\
\text { altered }\end{array}$ & $\begin{array}{l}\text { Amino acid } \\
\text { substitution }\end{array}$ \\
\hline rs1330344 & promoter & c. $-1676 C>T$ & $C=0.21$ & GATA-1, CdxA & \\
\hline rs883484 & promoter & c. $-8337 \mathrm{C}>\mathrm{T}$ & $G=0.04$ & ADR1 & \\
\hline rs1888943 & promoter & c. $-8759 \mathrm{C}>\mathrm{T}$ & $T=0.04$ & & \\
\hline rs913937 & promoter & c. $-9179 G>C$ & $C=0.05$ & & \\
\hline rs1236913 & exon 2 & c. $22 \mathrm{C}>\mathrm{T}$ & $T=0.09$ & & p.R8W \\
\hline rs3842787 & exon 2 & c. $50 \mathrm{C}>\mathrm{T}$ & $T=0.09$ & & p.P17L \\
\hline rs5787 & exon 4 & c. $323 G>A$ & $A=0.04$ & & p.R108Q \\
\hline
\end{tabular}

db: database; rs: reference SNP cluster; ID: identification; GATA: transcription factor recognising the DNA sequence (A/T)GATA(A/G); CdxA: chicken homeodomain transcription factor; MyoD: myogenic differentiation transcription factor; ADR1: alcohol dehydrogenase regulator $1 .{ }^{\#}: \mathrm{n}=160-176$; ${ }^{\circ}$ : from ATG start site. 


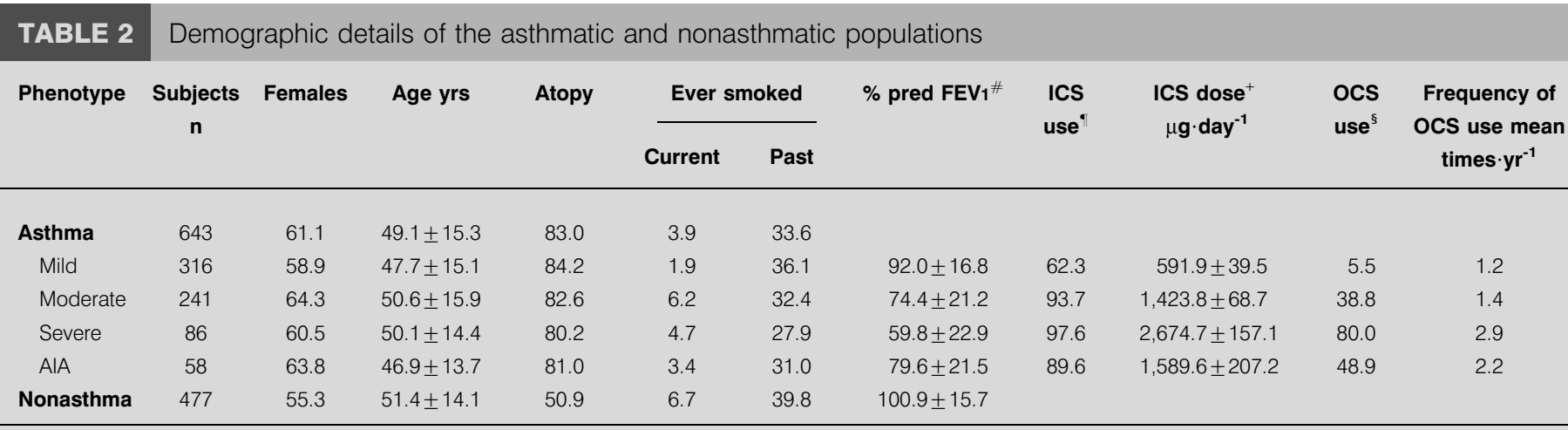

Data are presented as mean \pm SD or \%, unless otherwise indicated. FEV1: forced expiratory volume in one second; ICS: inhaled corticosteroid; OCS: oral corticosteroid;

\#: data for FEV1 was available for 310 mild, 237 moderate and 83 severe asthmatic patients, 48 aspirin-intolerant asthmatic (AIA) patients and 471 nonasthmatic subjects;

$\because$ : data for ICS use (beclomethasone equivalent dose) was available for 310 mild, 237 moderate and 85 severe asthmatic, and 48 AIA patients; ${ }^{+}$: data are presented as mean \pm SEM; ${ }^{\S}$ : data for OCS use was available for 309 mild, 237 moderate and 85 severe asthmatic, and 47 AIA patients.

for either the genotype or allele frequencies of these four polymorphisms. With a total of 457 control subjects, and based on the genotype and allele frequencies in table 3 , an $\alpha$ value $=0.05$ and a power of $90 \%$, minimum significant odds ratios (ORs) for genotype associations with asthma would have been 2.05 for c.-8592TT, 2.2 for c. $-1676 \mathrm{CC}$, and 4.25 for c.22TT and c.50TT. Similarly, the minimum significant
ORs for allelic associations would have been 1.61 for c.-8592T and c. $-1676 \mathrm{C}$, and 1.91 for c.50T and 2.0 for c.22T. Although the c.22T allele and the c.22CT genotype were slightly overrepresented among patients with moderate and severe asthma, these differences were not statistically significant $(p>0.17)$ and nor were the other polymorphisms associated with asthma severity. With 83 severe asthmatic patients, the minimum

TABLE 3 Genotype and allele frequencies for the common cyclooxygenase-1 polymorphisms

\begin{tabular}{|c|c|c|c|c|c|c|}
\hline Polymorphism & Genotype or allele & Control subjects & All asthmatic patients & Mild asthma & Moderate asthma & Severe asthma \\
\hline \multirow[t]{5}{*}{ c. $-8592 C>\mathbf{T} \mathbf{n}^{\#}$} & & 466 & 616 & 299 & 234 & 83 \\
\hline & $\mathrm{CC}$ & 63.3 & 62.7 & 61.2 & 63.3 & 66.3 \\
\hline & $\mathrm{TT}$ & 5.8 & 4.5 & 6.2 & 2.1 & 6.0 \\
\hline & C & 78.8 & 79.1 & 77.6 & 80.6 & 80.1 \\
\hline & $\mathrm{T}$ & 21.2 & 20.9 & 22.4 & 19.4 & 19.9 \\
\hline \multirow{5}{*}{ c. $-1676 C>\mathbf{T ~} n^{\#}$} & $\mathrm{CC}$ & 4.5 & 4.2 & 5.7 & 2.6 & 3.6 \\
\hline & CT & 34.3 & 34.5 & 33.2 & 38.9 & 26.5 \\
\hline & $\mathrm{TT}$ & 61.2 & 61.3 & 61.1 & 58.5 & 69.9 \\
\hline & C & 21.6 & 21.5 & 21.6 & 22.0 & 16.9 \\
\hline & $\mathrm{T}$ & 78.4 & 78.5 & 78.4 & 78.0 & 83.1 \\
\hline \multirow[t]{2}{*}{$\mathrm{c.22C}>\mathrm{T} \mathrm{n}^{\circ}$} & & 459 & 607 & 295 & 230 & 82 \\
\hline & $\mathrm{T}$ & 6.4 & 7.6 & 6.4 & 8.5 & 9.0 \\
\hline \multirow[t]{6}{*}{$\mathrm{c.50C}>\mathrm{T} \mathrm{n}^{+}$} & & 457 & 614 & 295 & 237 & 82 \\
\hline & $\mathrm{CC}$ & 85.1 & 87.8 & 88.1 & 86.9 & 89.0 \\
\hline & $\mathrm{CT}$ & 14.2 & 11.2 & 10.5 & 12.7 & 9.8 \\
\hline & $\mathrm{TT}$ & 0.7 & 1.0 & 1.4 & 0.4 & 1.2 \\
\hline & C & 92.2 & 93.4 & 93.4 & 93.2 & 93.9 \\
\hline & $\mathrm{T}$ & 7.8 & 6.6 & 6.6 & 6.8 & 6.1 \\
\hline
\end{tabular}

Data are presented as percentages of subjects with the particular genotype or allele within each group, unless otherwise stated. Comparison of genotype and allele frequencies showed no statistically significant differences between the groups ( $p>0.05){ }^{\#}: n=1,082 ;{ }^{\circ}: 1,066 ;{ }^{+}: n=1,071$. 
significant ORs for allelic associations would have been 2.8 for c. $-1676 \mathrm{C}$ and c. $-8592 \mathrm{~T}$, and 3.6 for c.50T and 3.8 for c. $22 \mathrm{~T}$.

AIA patients appeared to have a lower frequency of the c.$8592 \mathrm{~T}$ allele $(17.0 \%)$ compared with ATA patients $(21.6 \%)$, although the difference was not statistically significant. An apparent over-representation of the c.50TT genotype among AIA patients $(3.4 \%)$ compared with ATA patients $(0.8 \%)$ also did not reach statistical significance after adjustment for multiple testing $(\mathrm{p}=0.13)$. For 58 AIA patients, the minimum significant OR for association of the c.50TT genotype with AIA would have been 12.5 .

All subjects in this study were initially recruited as being either asthmatic or nonasthmatic, and their atopic status was then assessed by skin-prick testing at the time of inclusion in the study. Since these subjects should be approximately representative of a randomly recruited population of atopic and nonatopic subjects, associations with atopy as an independent phenotype were also assessed. An apparent under-representation of the c.22T allele among atopic (6.5\%) compared with nonatopic subjects $(8.4 \%)$ was not statistically significant (minimum significant $\mathrm{OR}=2.2$ ). The c.22TT genotype was, however, significantly more frequent among nonatopic $(1.2 \%)$ than atopic individuals $(0.1 \%$; OR $=9.05,95 \%$ confidence interval 1.01-81.29; $\mathrm{p}=0.034)$. This association was weak and its significance would be reduced by adjustment for multiple testing.

\section{Haplotype associations}

Strong linkage disequilibrium exists among the four informative SNPs (Lewontin $\mathrm{D}^{\prime} \geqslant 0.84$ ) and haplotype associations for these polymorphisms are shown in table 4. Global haplotype analysis showed no association with asthma $(p=0.46)$, asthma severity $(p=0.28)$ or AIA $(p=0.13)$. The wild-type CTCC haplotype was the most common and was present in $57 \%$ of the population. The other two major haplotypes were TTCC (21\%) and CCCC $(8 \%)$. None of these haplotypes were individually associated with asthma $(p \geqslant 0.32)$ or asthma severity $(p \geqslant 0.19)$. The strongest association was between AIA and the TTCC haplotype, but this was not significant after correction for multiple tests $(p=0.09)$, possibly because of the relatively small sample size of AIA patients.

\section{DISCUSSION}

This is the first comprehensive study to explore potential associations of COX-1 polymorphisms with asthma, disease severity, AIA and atopy. The allele frequencies of 20 previously reported polymorphisms in the promoter and coding region of the gene were determined in a random Caucasian population. Of the 20 previously reported SNPs, 10 were not detected in this population. Four of these (c.158G $>A$, c. $204 \mathrm{C}>\mathrm{T}$, c.554A $>\mathrm{C}$ and c.1022A $>\mathrm{G}$ ) have been previously reported to have variant allele frequencies of zero in Caucasians and $1-2 \%$ in African-Americans [20]. Another two SNPs that were not detected in the present Caucasian population (c.688G $>$ A, c. $1428 \mathrm{C}>\mathrm{T}$ ) had previously reported variant allele frequencies of $1 \%$ in Caucasians [20], while there is no published information on the frequencies of the other four SNPs (c.1076A>G, c.1327A > G, c.1399A > G, c. $-9169 C>G$ ) that were not detected in the present Caucasian population.

For most of the 10 polymorphisms that were present in the random Caucasian population, the variant allele frequencies were low, with the exception of the c.22T and c.50T alleles, which both had frequencies of $9 \%$. The c.50C $>\mathrm{T}$ and c.22C $>$ T SNPs were not only relatively frequent but also resulted in amino acid substitutions that are likely to affect COX-1 protein function [20]. The c.22C $>\mathrm{T}$ polymorphism results in the substitution of a positively charged arginine with an aromatic tryptophan residue (p.R8W), while the c.50C $>$ T polymorphism results in the substitution of a neutral proline with a hydrophobic leucine residue (p.P17L).

The c. $22 \mathrm{C}>\mathrm{T}$ and c.50C $>\mathrm{T}$ polymorphisms may also be functionally significant at the level of gene transcription, since the exonic splicing enhancer (ESE) finder program of CARTEGNI et al. [32] predicted that these polymorphisms may alter the binding of putative splicing factors (SR proteins) to the COX-1 gene. In contrast, although the c. $-1676 \mathrm{C}>\mathrm{T}$ and c. $-8592 \mathrm{C}>\mathrm{T}$ promoter polymorphisms were relatively frequent in the present populations, neither the transcription factor binding sites putatively deleted nor those created by these polymorphisms had any obvious relevance to asthma. Furthermore, these promoter polymorphisms did not affect the two Sp1 binding sites that have been reported to be essential for COX-1 transcription [19].

The c.22C $>$ T and c.50C $>$ T SNPs, as well as the two promoter polymorphisms (c. $-1676 \mathrm{C}>\mathrm{T}$ and c. $-8592 \mathrm{C}>\mathrm{T}$ ), were selected

\begin{tabular}{|c|c|c|c|c|c|c|c|}
\hline & \multirow{2}{*}{$\begin{array}{c}\text { Global haplotype } \\
\text { analysis }\end{array}$} & \multicolumn{6}{|c|}{ Haplotype specific scores } \\
\hline & & Стсс & TTCC & $\operatorname{cccc}$ & Ссст & сстс & Стст \\
\hline Asthma $^{+}$ & 0.46 & $57(0.77)$ & $21(0.96)$ & $8(0.67)$ & $7(0.62)$ & $7(0.32)$ & \\
\hline
\end{tabular}

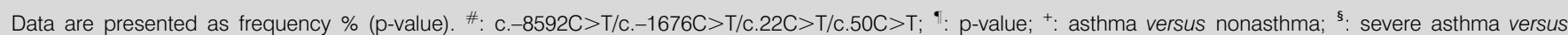
nonasthma; ${ }^{f}$ : aspirin-intolerant asthma versus aspirin-tolerant asthma. 
for detailed investigation in the current asthmatic and nonasthmatic populations. There were no allelic or genotypic associations between any of these polymorphisms and asthma or asthma severity. It could be argued that with allele frequencies of $<9 \%$ for c. $22 \mathrm{C}>\mathrm{T}$ and c.50C $>\mathrm{T}$, large populations would have to be studied in order to find an association. However, the populations of asthmatic and nonasthmatic individuals were bigger than in most other studies, and power calculations indicated that for most of the associations tested, the sample sizes in the present study had a power of $90 \%$ to detect ORs of $1.5-3$ as being statistically significant. Therefore, the study had reasonably adequate power to detect associations with asthma or asthma severity, and, despite the potential functional consequences of these COX-1 polymorphisms, any large effect on enzyme expression or activity in such a way as to influence the development or severity of asthma can be excluded.

However, a weak genotypic association was observed between c. $22 \mathrm{C}>\mathrm{T}$ (p.R8W) and atopy, suggesting that changes in the signal peptide of COX-1, which targets the protein for translocation into the endoplasmic reticulum [33], may be associated with some aspect of the allergic response. The current results suggest that the minor p.8W variant of COX-1 may provide a small protective effect against the development of atopy, which was defined in this study as the presence of at least one positive specific immunoglobulin $\mathrm{E}$ antibody response to inhaled allergens (positive skin-prick test). SNPs in a number of genes, including interleukin (IL)-4, IL-13, IL4RA [34], CD14 [35], Toll-like receptor 4 (TLR4) [36], and macrophage migration inhibitory factor [37], have been associated with an atopic phenotype, although not necessarily with asthma. The current authors have also recently demonstrated that a c. $-159 \mathrm{C}>\mathrm{T}$ polymorphism in the CD14 gene was very weakly associated with atopy, but not with asthma [38]. However, asthma and atopy share a common pathophysiological background and certain polymorphisms, such as those in the tumour necrosis factor- $\alpha$ gene are associated with both asthma and atopy [39]. The apparent weak association between atopy and the c.22C $>\mathrm{T}$ SNP may be the result of linkage disequilibrium with another polymorphism that is causally related to atopy, and the COX-1 gene is located in the same chromosomal region (9q32) as the TLR4 gene, which contains a SNP that has been linked with the severity of atopy [36]. Although atopic sensitivity may decrease with age, the atopic and nonatopic subjects in the present study spanned a similar age range, and no age adjustments were made when assessing associations with the current atopic phenotype of the subjects. However, the weak relationship between the c. $22 \mathrm{C}>\mathrm{T}$ polymorphism and atopy, and the possible influence of age, require further investigation.

Aspirin irreversibly inactivates COX-1 by acetylating an active site serine residue at position 530, near the carboxyl terminus of the protein [40]. Serine-530 is coded for in exon 11, but a search of the databases did not identify any nonsynonymous polymorphisms in exon 11 that would be likely to influence the pharmacological effects of aspirin. In the present study, there were no statistically significant associations between AIA and the c.22C $>\mathrm{T}$ or c.50C $>\mathrm{T}$ polymorphisms. Nevertheless, it is interesting that there was an over-representation of the c.50TT genotype (p.17LL) among AIA patients, as well as a haplotype association with AIA that, although possibly real, may not have reached statistical significance due to the relatively small sample size of AIA patients. The possibility of a link between p.P17L and the pharmacogenetics of aspirin is also supported by a recent report of the interaction between aspirin use and this polymorphism in relation to the risk of colorectal polyps [41].

Platelet responses to aspirin have been related to COX-1 genotype in a study of 38 healthy American Caucasian subjects [21]. In that study, a promoter polymorphism (c. $-842 \mathrm{~A}>\mathrm{G}$ ) that was not identified in the present screening analysis appeared to be in complete linkage disequilibrium with the c. $50 \mathrm{C}>\mathrm{T}$ polymorphism. Inhibition of $\mathrm{PGF} 2 \alpha$ formation by aspirin was greater in platelets from heterozygotes for the c.$842 \mathrm{~A}>\mathrm{G} / 50 \mathrm{C}>\mathrm{T}$ haplotype compared with platelets from wild-type homozygotes. In the only other study that has investigated COX-1 polymorphisms in relation to disease, linkage analysis showed that the c. $22 \mathrm{C}>\mathrm{T}$ and c.50C $>\mathrm{T}$ SNPs were not associated with an increased incidence of thrombosis in a large Vermont kindred population [42].

The present study has determined the allele frequencies of 20 polymorphisms in the promoter and coding region of the cyclooxygenase- 1 gene in random Australian Caucasian subjects, and four common polymorphisms were studied further in relation to asthma and atopy. This study, which was adequately powered, did not find any associations of any of the four individual polymorphisms or their haplotypes with asthma or asthma severity, suggesting that despite their potential functional importance, these promoter and coding region polymorphisms in the cyclooxygenase- 1 gene are unlikely to play a role in asthma. However, the results from the study did indicate that the c.22TT genotype may confer a small protective effect against atopy. In addition, a possible association between the c.50TT genotype and aspirinintolerant asthma, as well as a possible haplotype association with aspirin-intolerant asthma, were identified, and may warrant further investigation in a larger population of aspirinintolerant asthma patients.

\section{ACKNOWLEDGEMENTS}

The authors would like to thank the patients who participated in this study, F. Lose and the staff at the Asthma and Allergy Research Institute and the Australian Red Cross Blood Service (Perth, Australia). The authors also thank K. Fong (The Prince Charles Hospital, Brisbane, Australia), R. O'Hehir and F. Thien (The Alfred Hospital, Melbourne, Australia) who assisted with the collection of clinical information and blood samples.

\section{REFERENCES}

1 Knight DA, Stewart GA, Lai ML, Thompson PJ. Epithelium-derived inhibitory prostaglandins modulate human bronchial smooth muscle responses to histamine. Eur J Pharmacol 1995; 272: 1-11.

2 Pavord D, Tattersfield AE. Bronchoprotective role for endogenous prostaglandin $E_{2}$. Lancet 1995; 345: 436-438.

3 Gauvreau GM, Watson RM, O'Byrne PM. Protective effects of inhaled $\mathrm{PGE}_{2}$ on allergen-induced airway responses and airway inflammation. Am J Respir Crit Care Med 1999; 159: 31-36. 
4 Vane JR, Bakhle YS, Botting RM. Cyclooxygenases 1 and 2. Annu Rev Pharmacol Toxicol 1998; 38: 97-120.

5 Helliwell RJ, Adams LF, Mitchell MD. Prostaglandin synthases: recent developments and a novel hypothesis. Prostaglandins Leukot Essent Fatty Acids 2004; 70: 101-113.

6 Chandrasekharan NV, Dai H, Lamar Turepu Roos K, et al. COX-3, a cyclooxygenase-1 variant inhibited by acetaminophen and other analgesic/antipyretic drugs: cloning, structure, and expression. Proc Natl Acad Sci USA 2002; 99: 13926-13931.

7 Dubois RN, Abramson SB, Crofford L, et al. Cyclooxygenase in biology and disease. FASEB J 1998; 12: 1063-1073.

8 Long JA, Fogel-Petrovic M, Knight DA, Thompson PJ, Upham JW. Higher prostaglandin E2 production by dendritic cells from subjects with asthma compared with normal subjects. Am J Respir Crit Care Med 2004; 170: 485-491.

9 Smith WL, DeWitt DL, Garavito RM. Cyclooxygenases: structural, cellular and molecular biology. Annu Rev Biochem 2000; 69: 149-182.

10 Demoly P, Crampette L, Lebel B, Campbell AM, Mondain M, Bousquet J. Expression of cyclo-oxygenase 1 and 2 proteins in upper respiratory mucosa. Clin Exp Allergy 1998; 28: 278-283.

11 Watkins DN, Peroni DJ, Lenzo JC, Knight DA, Garlepp MJ, Thompson PJ. Expression and localization of COX-2 in human airways and cultured airway epithelial cells. Eur Respir J 1999; 13: 999-1007.

12 Pang L, Pitt A, Petkova D, Knox AJ. The COX-1/COX-2 balance in asthma. Clin Exp Allergy 1998; 28: 1050-1058.

13 Szczeklik A, Stevenson DD. Aspirin-induced asthma: advances in pathogenesis, diagnosis, and management. $J$ Allergy Clin Immunol 2003; 111: 913-921.

14 Hedman J, Kaprio J, Poussa T, Nieminen MM. Prevalence of asthma, aspirin intolerance, nasal polyposis and chronic obstructive pulmonary disease. Int J Epidemiol 1999; 28: 717-722.

15 Szczeklik A, Nizankowska E, Duplaga M. Natural history of aspirin-induced asthma. AIANE Investigators. European Network on Aspirin-Induced Asthma. Eur Respir J 2000; 16: 432-436.

16 Vally H, Taylor ML, Thompson PJ. The prevalence of aspirin intolerant asthma (AIA) in Australian asthmatic patients. Thorax 2002; 57: 569-574.

17 Szczeklik A, Nizankowska E, Bochenek G, Nagraba K, Mejza F, Swierczynska M. Safety of a specific COX-2 inhibitor in aspirin-induced asthma. Clin Exp Allergy 2001; 31: 219-225.

18 Wang LH, Hajibeigi A, Xu XM, Loose-Mitchell D, Wu KK. Characterization of the promoter of human prostaglandin H synthase-1 gene. Biochem Biophys Res Commun 1993; 190: 406-411.

19 Xu XM, Tang JL, Chen X, Wang LH, Wu KK. Involvement of two Sp1 elements in basal endothelial prostaglandin $\mathrm{H}$ synthase-1 promoter activity. J Biol Chem 1997; 272: 6943-6950.

20 Ulrich CM, Bigler J, Sibert J, et al. Cyclooxygenase 1 (COX1) polymorphisms in African-American and Caucasian populations. Hum Mutat 2002; 20: 409-410.
21 Halushka MK, Walker LP, Halushka PV. Genetic variation in cyclooxygenase 1: effects on response to aspirin. Clin Pharmacol Ther 2003; 73: 122-130.

22 Shi J, Misso NL, Duffy DL, Thompson PJ, Kedda MA. A functional polymorphism in the promoter region of the cyclooxygenase-2 gene is not associated with asthma and atopy in an Australian population. Clin Exp Allergy 2004; 34: 1714-1718.

23 Szczeklik W, Sanak M, Szczeklik A. Functional effects and gender association of COX-2 gene polymorphism G-765C in bronchial asthma. J Allergy Clin Immunol 2004; 114: 248-253.

24 National Asthma Council, Australia. Asthma Management Handbook. South Melbourne, National Asthma Council Australia Ltd, 2002.

25 National Institutes of Health, National Asthma Education and Prevention Program, Expert Panel Report II. Guidelines for the Diagnosis and Management of Asthma. Bethesda, NIH, 1997. Publication No. 97-4051.

26 Kedda MA, Shi J, Duffy DL, et al. Characterisation of two polymorphisms in the leukotriene $\mathrm{C} 4$ synthase gene in an Australian population of subjects with mild, moderate, and severe asthma. J Allergy Clin Immunol 2004; 113: 889-895.

27 Riva A, Kohane IS. SNPper: retrieval and analysis of human SNPs. Bioinformatics 2002; 18: 1681-1685.

28 Tatusova TA, Madden TL. BLAST 2 sequences, a new tool for comparing protein and nucleotide sequences. FEBS Microbiol Lett 1999; 174: 247-250.

29 R Development Core Team. R: A language and environment for statistical computing. Vienna, R Foundation for Statistical Computing, 2003. www.R-project.org.

30 Schaid DJ, Rowland CM, Tines DE, Jacobson RM, Poland GA. Score tests for association between traits and haplotypes when linkage phase is ambiguous. Am J Hum Genet 2002; 70: 425-434.

31 Heinemeyer T, Wingender E, Reuter I, et al. Databases on transcriptional regulation: TRANSFAC, TRRD and COMPEL. Nucleic Acids Res 1998; 26: 362-367.

32 Cartegni L, Wang J, Zhu Z, Zhang MQ, Krainer AR. ESEfinder: A web resource to identify exonic splicing enhancers. Nucleic Acids Res 2003; 31: 3568-3571.

$33 \mathrm{Li} \mathrm{Y,} \mathrm{Smith} \mathrm{T,} \mathrm{Grabski} \mathrm{S,} \mathrm{DeWitt} \mathrm{DL.} \mathrm{The} \mathrm{membrane}$ association sequences of the prostaglandin endoperoxide synthases-1 and -2. J Biol Chem 1998; 273: 29830-29837.

34 Liu X, Beaty TH, Deindl P, et al. Associations between specific serum $\operatorname{IgE}$ response and 6 variants within the genes IL4, IL13, and IL4RA in German children: The German Multicenter Atopy Study. J Allergy Clin Immunol 2004; 113: 489-495.

35 O'Donnell AR, Toelle BG, Marks GB, et al. Age-specific relationship between CD14 and atopy in a cohort assessed from age 8 to 25 years. Am J Respir Crit Care Med 2004; 169: 615-622.

36 Yang IA, Barton SJ, Rorke S, et al. Toll-like receptor 4 polymorphism and severity of atopy in asthmatics. Genes Immun 2004; 5: 41-45.

37 Hizawa N, Yamaguchi E, Takahashi D, Nishihira J, Nishimura M. Functional polymorphisms in the promoter region of macrophage migration inhibitory factor and atopy. Am J Respir Crit Care Med 2004; 169: 1014-1018. 
38 Kedda MA, Lose F, Duffy D, Bell E, Thompson PJ, Upham J. The CD14 C-159T polymorphism is not associated with asthma or asthma severity in an Australian adult population. Thorax 2005; 60: 211-214.

39 Shin HD, Park BL, Kim LH, et al. Association of tumor necrosis factor polymorphisms with asthma and serum total IgE. Hum Mol Genet 2004; 13: 397-403.

40 DeWitt DL, el-Harith EA, Kraemer SA, et al. The aspirin and heme-binding sites of ovine and murine prostaglandin endoperoxide synthases. I Biol Chem 1990; 265: 5192-5198.

41 Ulrich C, Bigler J, Sparks R, et al. Polymorphisms in PTGS1 $(=\mathrm{COX} 1)$ and risk of colorectal polyps. Cancer Epidemiol Biomarkers Prev 2004; 13: 889-893.

42 Scott BT, Hasstedt SJ, Bovill EG, et al. Characterization of the human prostaglandin $\mathrm{H}$ synthase 1 gene (PTGS1): exclusion by genetic linkage analysis as a second modifier gene in familial thrombosis. Blood Coagul Fibrinolysis 2002; 13: 519-531. 